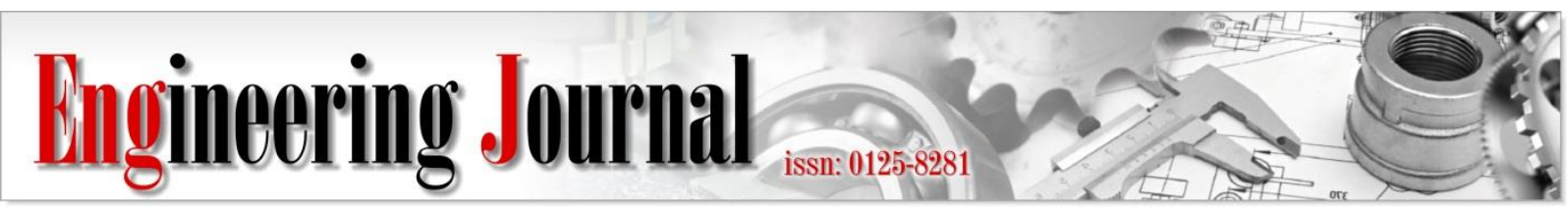

Article

\title{
Modularization of Ship Engine Room Using Design Structure Matrix (DSM) Based on The Genetic Algorithm
}

\author{
Gunawan $^{\mathrm{a}, *}$, Yanuar ${ }^{\mathrm{b}}$, Farhan Aji Waskita $^{\mathrm{c}}$ and Arif Kurniawan ${ }^{\mathrm{d}}$ \\ Department of Mechanical Engineering, Universitas Indonesia, Indonesia \\ E-mail: agunawan_kapal@eng.ui.ac.id (Corresponding author), byanuar@eng.ui.ac.id, \\ cfarhanajiwaskita@gmail.com, dzikrulmizan@gmail.com,
}

\begin{abstract}
Recently, the shipbuilding industry has been able to develop new production methods. These new methods promote design automation in order to produce ships more efficiently. The various production concepts, like block division, modularization and building ships with a standard design are possible solutions for improve production. Engine room design, including the piping system, is a complex process; therefore, modularization of its design is an effective strategy to minimize the complexity of the system. In addition, modularization plays an important role. This process requires a considerable number of man hours. This paper presents a new approach for engine room design based on the modularization concept. The characteristics of the proposed method are as follows: • Attention was paid to all piping systems of ship engine room. The cost and weight of the piping system were considered. $\bullet$ To define an effective module, a design structure matrix was adopted. - In the modularization using DSM, the Genetic algorithm is used to obtain modules by considering some constraints like number of pipe connections and pipe cost. This study discusses the details of the above mentioned methods. In addition, simulation test of design optimization of a several piping systems were carried out to illustrate the design optimization procedure in detail and to verify the effectiveness of the proposed methodology.
\end{abstract}

Keywords: Modularization, piping system, design structure matrix (DSM), genetic algorithm.

ENGINEERING JOURNAL Volume 24 Issue 4

Received 5 December 2019

Accepted 21 April 2020

Published 31 July 2020

Online at https://engj.org/

DOI:10.4186/ej.2020.24.4.205 


\section{Introduction}

As the world keeps on growing, the amount of information in engineering studies also continues to grow, in order to compete, every industry must continue to develop techniques to provide the user demands. Engineers have to improve the production and achieve higher values of design efficiency to continually remains in business. A variety of products are required to satisfy costumers needs in both niche and mainstream markets. Because of the difficulty to achieve a good balance between product variety and product quality, the various production concepts, i.e. modularization concept, block division and building ships with a standard design, are possible solutions to improving both the variety and quality of the products. In shipbuilding, the engine rooms of ship, including the piping system, is a complex process. therefore, modularization of its design is an effective strategy to reduce the complexity of the system. In shipbuilding, the piping design, arrangement of the piping system and the specification of the piping system differ significantly because the differences in ship sizes. These differences occur because of the individual ship designs are developed exclusively owing to different equipment used by the ship owners as well as different engine-room requirements.

Considering the characteristics of piping-system design in shipbuilding applications, it is important for shipbuilders to develops a method based on standard modularization while considering the variety of different sizes series of ships. The development of a standard module arrangement is also important for achieving overall design optimization. Concepts of engine-room modularization was first developed by several researches, Cort and Hills (1987) [1], Hills and Wels (1989) [2]. However, these studies resort to a simple modularization approach that involves a standard compartment use for each ship. Afterwards, the concepts to simplify the construction of outfitting and equipment used in the engine room was first introduced by Jaquith et al. (1996) [3]. In these studies, big data system was adopted to identify all components in the engine room. Baade et al., (1998) explored the modularization concept based on grouping of system components inside an engine room, they proposed in the form of a modular standard container, based on function volume [4]. In these studies, they considered a standard modular frame. Tommasoni et al. (2003) proposed an advanced design methodology of grouping machinery equipment into a functional volume, block, and an interference that considered between them [5]. Furthermore, the implementation of DSM methodology in engineering study was tested by Sosa et al. (2003) used a longitudinal set of static DSMs to analyze the dynamics of evolving products [6]. MacCormack et al. (2006) proposed the architecture DSM to redesign the complex software in to simpler [7]. Furthermore, Schmidt et al. (2009) proposed DSM applications at NASA, Boeing and General Motors [8]. Dong and Whitney (2001) implemented DSM concept in order to develop the chemistry analyzer [9]. In the aircraft industry, Clarkson et al. (2004) and Eckert et al. (2004) introduced the DSM to change the propagation in complex design $[10,11]$.

Table 1. Summary of previous studies

\begin{tabular}{lccccll}
\hline \multicolumn{1}{c}{ Authors } & \multicolumn{2}{c}{ Objective } & \multicolumn{2}{c}{ Methods } & Target Studies \\
\cline { 2 - 5 } & $\begin{array}{l}\text { Modulariz } \\
\text { ation }\end{array}$ & $\begin{array}{l}\text { Arrangem } \\
\text { ents }\end{array}$ & $\begin{array}{l}\text { Pipe } \\
\text { Routing }\end{array}$ & GA & Rule/ Others & \\
\hline Jaquith et al. [3] & O & X & X & X & Manual & One ship \\
Baade et al. [4] & O & O & X & X & Manual & One ship \\
Tomassoni et al. [5] & O & O & X & X & ERAM & One ship \\
Hills and Wells [2] & O & O & X & X & Manual & One ship \\
Schmidt et al. [8] & O & O & X & X & DSM & Automobile \\
Sosa et al. [6] & O & O & X & X & DSM & Software \\
Koga et al. [12] & O & O & X & X & DSM & Components \\
Cort and Hills [1] & O & O & X & X & Manual & One ship \\
MacCormack et al. [7] & O & X & X & X & DSM & Software \\
Dong and Whitney [9] & O & X & X & X & DSM & Gas Analyzer \\
Clarkson et al. [10] & O & X & X & X & DSM & Aircraft \\
Eckert et al. [11] & O & X & X & X & DSM & Aircraft \\
Rubesa et al. [13] & O & X & X & X & Rule Base & One ship \\
Erikstad [14] & O & X & X & X & Rule Base & One ship \\
Kim et al. [15] & X & O & O & X & Fuzzy & Components \\
Kimura [16] & X & X & X & O & SA & Components \\
Wu et al. [17] & X & O & O & X & Fuzzy & Components \\
Lee et al. [18] & X & O & O & X & Rule Base & Components \\
Helvacioglu et al. [19] & X & O & X & X & Rule Base & Components \\
Niu et al. [20] & X & X & O & O & X & One ship \\
\hline
\end{tabular}


Rubesa et al. (2011) introduced new concept of estimate the effectiveness of ship modular outfitting. This research analyzes the modular outfitting effectiveness using some constraint conditions [13]. Erikstad (2009) reported the significant of modular product in order to reduce the production lead time in shipbuilding industry [14].

Nowdays, many industries have moved from designing individual towards developing product platforms from which a large number of variants or customized products can be configured. There are numerous cases from diverse industries on how this technology has improved the product development process. For instance, Volkswagen has applied platform technology across their Audi, Volkswagen, Seat and Skoda brands. Black \& Decker has developed a common platform with extensive component reuse both across different brands and across different product types. Sony developed a platform on which they developed and delivered a stream of Walkmans models over many years. The benefits reported are reduced cost, shorter development cycles and the ability to maintain a broad product range while standardizing and reducing the number of different components and configuration elements, Wuuren and Halman (2001) [21].

The other researches related to the modularization, arrangement and pipe routing in ship building industry are proposed by Kim et al. (2009) [15], Kimura (2011) [16], Wu et al. (1998) [17], Lee et al. (2013) [18], Helvaciogle et al. (2005) [19] and Niu et al. (2016) [20]. However, most of them focused on the arrangement and pipe routing.

Modularity in production systems aims at building production systems from standardized modular machines. The fact that a wide diversity of production requirements exists has led to the introduction of a variety of production machinery and a lack of agreement on what the building blocks should be. This means that there are no standards for modular machinery. In order to build a modular production system, production machinery must be classified into functional groups from which a selection of a modular production system can be made to respond to different production requirements. Rogers and Bottaci (1997) classifies production machinery into four basic group of "primitive" production elements. These are process machine primitives, motion units, modular fixtures, and configurable control units [22]. It is argued that if a selection is made from these four categories, it will be possible to build a diverse range of efficient, automated, and integrated production systems.

The other researches are focused on the arrangement optimization. Automatic arrangement is the placement of several components in the target space by considering some constraints. In the automatic arrangement, the optimization algorithm is required. The computer assistance is required because of its ability to handle tedious computations and evaluations very rapidly, far more rapidly than is practical by human brain power with the aid of pencil and paper. It is this characteristic that makes the computer important to the more successful attempts to improve arrangement design techniques.

However, computer technology coupled with the mathematician's brain power is not yet to the point where it is practical to deterministically evolve an optimum arrangement. Therefore, some optimization techniques like heuristic procedure are required. Using the heuristic technique i.e. genetic algorithm is powerful way to obtain the optimized arrangement in the complicated problem. Developing machinery arrangement is an important step because of the impact of the layout on the operation, repair, and maintenance of the machinery. Because of the complex and precise nature of the machinery arrangement layout, many researchers have proposed various approaches to assist in the layout design such as exact procedures, heuristics, neural networks, fuzzy logic, and expert system. Automatic arrangement is required to solve the complicated problem of part arrangement inconsideration some constraints condition. Using some algorithm as denote above, the automatic arrangement method is easier to meet the optimized arrangement in the several applications.

In the industrial park, the plant arrangement design is the keyway to help enterprise improving production efficiency, operation safety and energy saving. In the petroleum factory, the arrangement of plants is very important due to the reducing of the piping cost and material flow. In order to optimize the plant arrangement, Wu et al. (2016) proposed the optimization method using Genetic Algorithm (GA) [23]. The objective function in their study is to minimize the total pipeline cost and the economic property damage which is caused by safety accidents simultaneously.

The problem of plant layout optimization also studied by Lee (2015) [24]. After selecting the type of a process and determining the specifications of all equipment, the next step is to design a plant layout how to determine the location of each process units in an area with significant engineering creativities, heuristics, prior knowledge, and so on. Thus, the total construction cost is the combination of the purchasing equipment cost, the piping cost and the site cost. Moreover, a plant layout should secure enough maintenance and safety spaces for efficient accessibilities and safety requirements to repair process units and prevent domino impacts. In addition, in case of off-shore plants, multi-floor processes have to be installed in the limited site. These issues make the plant layout problems very difficult and complex. In order to solve above problem, Lee proposed the optimization method using the particle swarm optimization (PSO).

Table 1 shows a summary of previous studies about the application of the genetic algorithm methods and rule based algorithm in ship building. As can be seen form the table 1 , the modularization is addressed only in several components of engine room area using the DSM concept. Most of them, modularization is proposed using manual methods based on the experience of the designer.

Modularization is decomposition of a product into building block (modules) with specified interfaces, driven 
by company-specific strategies. The product of modularization (module) is defined as having two characteristics: 1) similarity between the physical and functional architecture of the design, and 2) minimization of the degree of interaction between physical components. In other word, module is a set of components grouped because of certain relationships, suggested through analysis of the product architecture tool and defined to comprise a module or subsystem. The difference between a module and a subassembly should be noted. A sub assembly is often the result of the assembly planning activity. Subassemblies are created because the product design does not permit entire assembly in one flow.

Most design problems can be broken down into a set of easy-to-manage simpler sub-problems. Sometimes complex problems are reduced into easier sub-problems, where a small change in the solutions of one sub-problem can lead to a change in other sub-problems' solutions. This means that the decomposition has resulted in functionally dependent sub-problems. Modularity focuses on decomposing the overall problem into functionally independent sub-problems, in which interaction or interdependence between sub-problems is minimized. Thus, a change in the solution of one problem may lead to a minor modification in other problems, or it may have no effect on other sub-problems.

Accordingly, in this paper discussed about a new modularization concept for one ship including all components in the engine room using DSM method. In order obtain the best solution, genetic algorithm is adopted. The proposed concept is used in an actual ship design process and the effectiveness is evaluated.

\section{Problem definition}

\subsection{Target ship}

The target ship of this research is bulk carrier with total piping system. The piping system in the engine room is classified into a fuel system, lubricating oil system, seawater system, freshwater system, compress air system, and steam system.

\subsection{Target process}

The piping design process generally consist of the following four stages: Owner Requirements, Piping Diagram, Part Arrangements, and Pipe Routing. Each ship has different part arrangements according to the above stated flow design. This paper focus on modularization of parts in engine room, hence, the piping diagram is already fix and the piping route is not considered.

\section{Methodology}

The main objective of this study was to develop a method of modulating the parts of the engine room using the concept of modularization based on the rules of genetic algorithm. Modularization involves the relationship between parts, the parts that have the strongest relationships will be grouped in one section. The result of this process is a simpler arrangement of the initial arrangement. The module requirements are as follows.
- Module should be applicable for a single ship, a series ships, and for various types of series ships.

- To apply the concept of modularization effectively, the complex connection between parts must be included in the module. Hence, the connection between the module must be minimized.

DSM is a network modeling tool used to represent elements that pervade a system and their interactions. DSM is particularly suitable for applications with complex structure development for engineered system, the basic procedure of DSM is to divide a complex system into subsystems and components, also identifying the known interactions between each component and represent these using mark or values in matrix. DSM usually illustrated as a square matrix, mapping the interactions among the set of system elements. Using DSM in modelling system, we are able to understand networks interactions of complex systems, yielding two primary types of benefits, architecture benefits and integration benefits.

The DSM is represented as a square $\mathrm{N} x \mathrm{~N}$ matrix and the interactions among the set of $\mathrm{N}$ elements are mapped. DSM has been effectively used to model several types of systems. In the product architecture, the DSM elements would be the components of the product and the interactions would be the interface between the components. This explanation is depicted by Eppinger and Browning (2012) [25], Lindemann et al., (2009) [26] and Kamrani and Salhieh, (2002) [27]. Depending on the type of system being modelled, DSM can represent various types of architectures.

Compared with other network modelling methods, the primary benefit of DSM is the graphical nature of the matrix display format. The matrix provides a highly compact, easily scalable, and intuitively readable representation of a system architecture. DSM has been used by number of researchers and practitioners for product architecture analysis. Depending on the context or author, these DSM have been given many different names, including product architecture DSM, product DSM, and component-based DSM. In all of these cases, this type of DSM model represents the components comprising a product and the relationships between them. Using product architecture DSM models, many researchers and industrial practitioners have been able to better understand networks of interactions in complex systems, yielding two primary types of benefits:

- Architecture benefits: planning subsystems or modules, understanding connections across subsystems or modules, identifying the impact of new technology, assessing the match between technical and organizational architectures, designing for modularity, designing for adaptability.

- Integration benefits: planning necessary integration and test activities at component, module, and subsystem levels; identifying 
problematic interactions that may present integration challenges.

The basic procedure for building as product architecture DSM is as follows:

Decompose the overall product or system into its subsystems or components. Make the entity-relationship model to identify the all components/parts interaction. Lay out the square DSM with components labeling the rows and columns, grouped into subsystems or modules if appropriate. Identify the known interactions between the components and represent these using marks or values in the DSM cells.

Certainly, the modularization concept is not the new method in order to solve the piping design problem, however, in this study the modularization concept is different with the modularization concept in the previous related studies. In the previous studies, generally, module is defined as the subsystem of the main engine room components. Consequently, module is define as a functional volume of system unit inside engine room like fuel oil module, sea water cooling module, fuel oil module and so on. However, in this research, the module is defined as the group of components with strong connection. Therefore, each system inside engine room like sea water cooling system will be modularized in to several modules.

The modularization concept is proposed for all series ships. In a word, all piping system in 100 ships will be modularized simultaneously. Basically, the piping system for each ship is similar. However, according to the differences of the owner requirements, certain ship has different component in several piping system. Therefore, these components are categorized as optional components For this reason, the modularization is divided into two kinds; common modularization for common components and optional modularization for optional components. Each series is different in size; consequently the size of component may be different. The differences of components are not considered in the modularization. The most important point in the modularization is composing common module for all ships in all series. In the previous related studies, the commonness module is not considered because the target ship is only single ship or only several components.

The fist step for modularization process is selecting the piping diagram. To establish relationships between the various parts in the piping diagram, this study uses the entity-relationship model (E-R model). The E-R model graphically represents the logical relationships of entities (objects). The model was first proposed by Peter Pin-Shan Chen of Massachusetts Institute of Technology (1970) [28]. In E-R modelling, the objects are represented by an entity, a relationship, and attributes. The detail of these can be defined as follows:

- An entity is a thing that exists either physically or logically.
- Relationships denote the manner in which the entities are related to one another.

- Attributes are the properties of entities.

In this research, the piping diagram is expressed by entity-relationship model. For the example, the entities are: the cooler, heater, purifier, filter, etc. The valve and branch are also considered as entities. Then, a relationship is the pipe connection between the entities. Finally, the flow capacity, heating value, part size, pipe diameter, etc. are considered as attributes. E-R model is composed for each piping system. Therefore, six E-R models are composed for each ship. The relationship between the entities is represented by a pipe connection.

Subsequent to the generation of the E-R model for each ship, the E-R models are integrated into a single E-R model with specific focus on entities and their relationships. The important point that the attributes are different, the entities and relationship are the same. The entities, in this case, are estimated to be similar; therefore, similar entities and relationships are integrated into a single entity or single relationship. Thereafter, the entities and relationship are classified into the following two types.

- Common entities and relationship: these entities and relationship are used in all types of ships. In this case, the pump, cooler, and generator are the common entities.

- Optional entities and relationships: these entities and relationship are used in a few of the ships, i.e. a series of ships, or ships for certain owners. In this case, the purifier and heater are the optional entity in ship 1 and the filter is the optional entity in ship 2. Integration of E-R model is executed considering the requirements of each ship.

The most common method of analysis applied to product architecture DSM models is called clustering. This is a form of partitioning analysis that reorders the rows and columns of the DSM to group the components according to some objective, which usually pertains to the number and strength of the interactions. Clusters or modules may be formed to group components that may achieve efficiencies through common supplier, sharing multiple interfaces, or having complex interactions may be candidates for a cluster/module.

DSM using rule-based algorithms includes 2 steps, reordering and clustering. Here are the several proposition for reordering in DSM, the first one is boundaries, understanding the limits of the designated system. The second one is interaction types, grouping various types of components based on their connections and relationship. The third one is interaction strengths, considering the level and degree of each elements connection using a numerical DSM. The fourth one is symmetry, most product in DSM are symmetry but it is not guarantee that every interaction in DSM components are symmetry, and the last one is identifying interactions between each connections. 


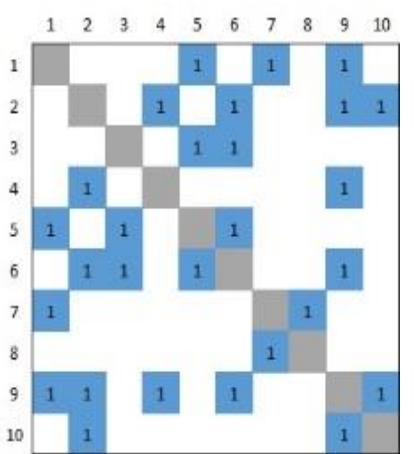

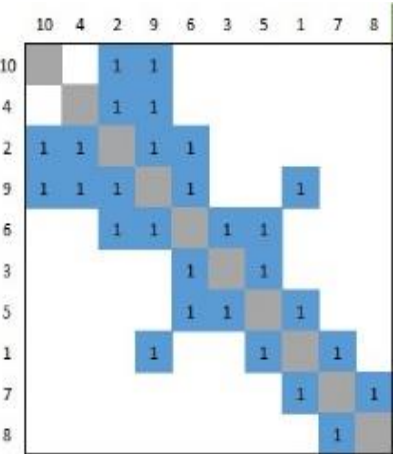

b

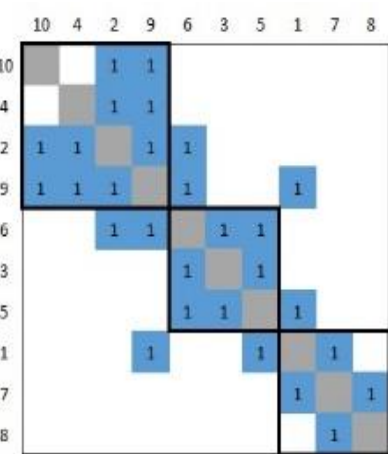

C

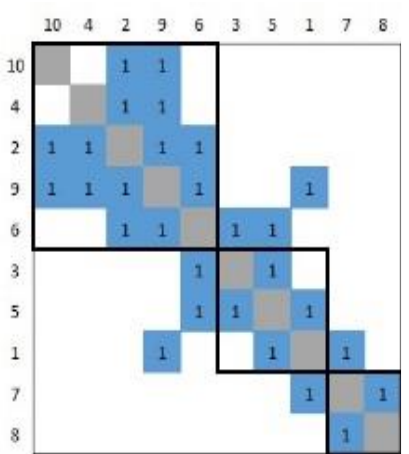

$d$

Fig. 1. (a) Original Matrix. (b) Reordered Matrix. (c) Clustered Matrix Form 4,3,3 with Objective Value $=760$.

(d)Clustered Matrix Form 5,3,2 with Objective Value $=960$.

Figure 1 shows the reordering and clustering process. It can be seen that the original matrix noted in figure 1.a with 10 components. Then using the reordering algorithm, the matrix is reordered in to figure 1.b. The next step is clustering. In this step, some possibilities form is generated. However, using the objective function, the best one is selected. Based on the figure 1, we conclude that the difference of objective value between two clustered matrix caused by the cluster form, which as we see the $2,4,4$ form shows the smaller objective value instead of 3,3,4 form due the components outside the module in $2,4,4$ form is fewer than the 3,3,4 form. Therefore, the smallest objective function representing more effectiveness and efficient grouping of the components for a system.

The reordering process which discussed in this paper are component based DSM using genetic algorithm methods. The purpose of this method is to move the fill node as close as the diagonal by using reordering the order of the matrix, in the other hand, the configuration with minimum real sum value of matrix configuration is the best configuration.

After the initial DSM reordered then the next step is decide the optimum module. Clusters may be formed to group components that my achieve efficiencies through common membership in the cluster. For example, several components produced by a common supplier, sharing multiple interfaces, or having complex interactions may be candidates for a cluster.

Clustering is essentially a type of assignment problem seeking the optimum allocation of the $\mathrm{N}$ components to $\mathrm{M}$ clusters. Clustering algorithms have many applications besides the DSM, and a variety of algorithms is available. However, a DSM clustering analysis presents several potential challenges.

Clustering is essentially a type of assignment problem seeking the optimum allocation of the $\mathrm{N}$ components to $\mathrm{M}$ clusters. Clustering algorithms have many applications besides the DSM, and a variety of algorithms is available.
However, a DSM clustering analysis presents several potential challenges. Clustering objective functions for DSM analysis trade off two conflicting goals: (1) minimize the (number and/or strength of) interactions outside clusters, and (2) minimize the size of the clusters.

Nevertheless, the objective function to be minimized considers both the size of the clusters $(C)$, $a$ is the sum of columns/rows (10), b is the product of rows with column (100) and I is the number of outside cluster, according to the following equation:

$$
O b j=a \sum_{i=1}^{M} c^{2}+b l
$$

Clustering analysis also requires attention to the following considerations:

- Number of clusters. What should be the bounds on M? Without any bounds, an objective function might find it optimal just to call the whole DSM a single cluster $(\mathrm{M}=1)$ or to call each components a separate cluster $(M=N)$, although neither of these extreme solutions is typically desirable.

- Cluster size. A related consideration is if and how to bound the size of each cluster. Usually, a lower bound of a cluster consisting of a single component should be allowed. However, it may be necessary to constraint the maximum number of components that can be assigned to a cluster. Allowing size of clusters to increase essentially limits the maximum number of clusters.

- Interaction types. The interaction type is the most important point to decide the clustering analysis. There are some examples of interactions: material flow, pipe connection, energy transfer, etc.

In this study, the number of cluster can be varied based on the requirement from the user. The number of cluster effect to the cluster size. Then, the interaction type in this study is pipe connection so the matrix is categorized as the symmetrical matrix DSM. 


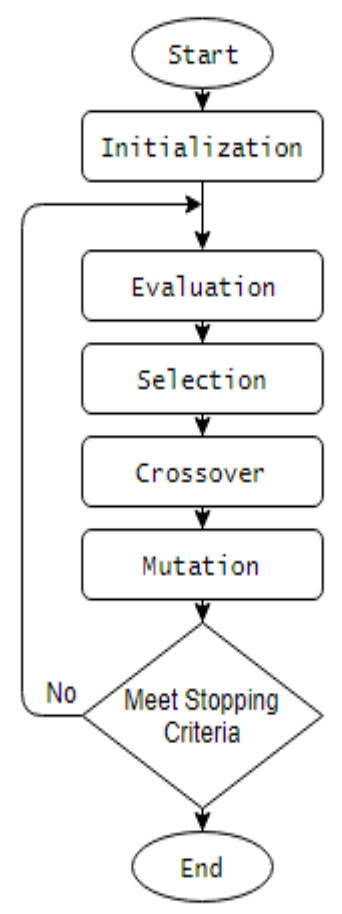

(a)
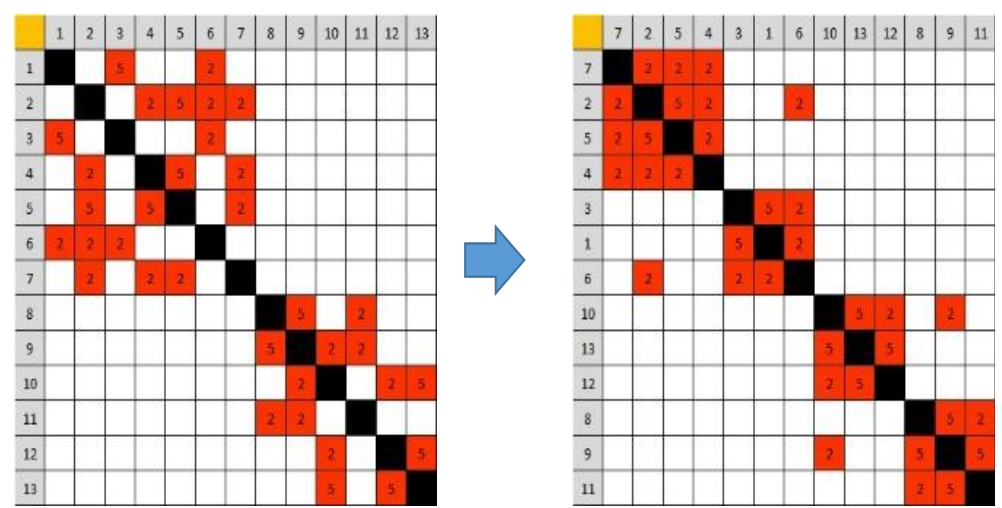

(b)

Fig. 2. (a) Flow Chart of genetic algorithm. (b) Result of reordering DSM using genetic algorithm.

After reordering process, the important step is clustering. In this study, clustering is performed using the weighted DSM. First, the matrices for common parts and optional parts are generated separately. Subsequently, the weights of the connections are set by the following rules:

- Connections for the common parts: The weight is assumed as the cost of the unit length of the corresponding pipe. When two or more pipes exist between the target parts, weight is assumed as the sum of the cost of corresponding pipes.
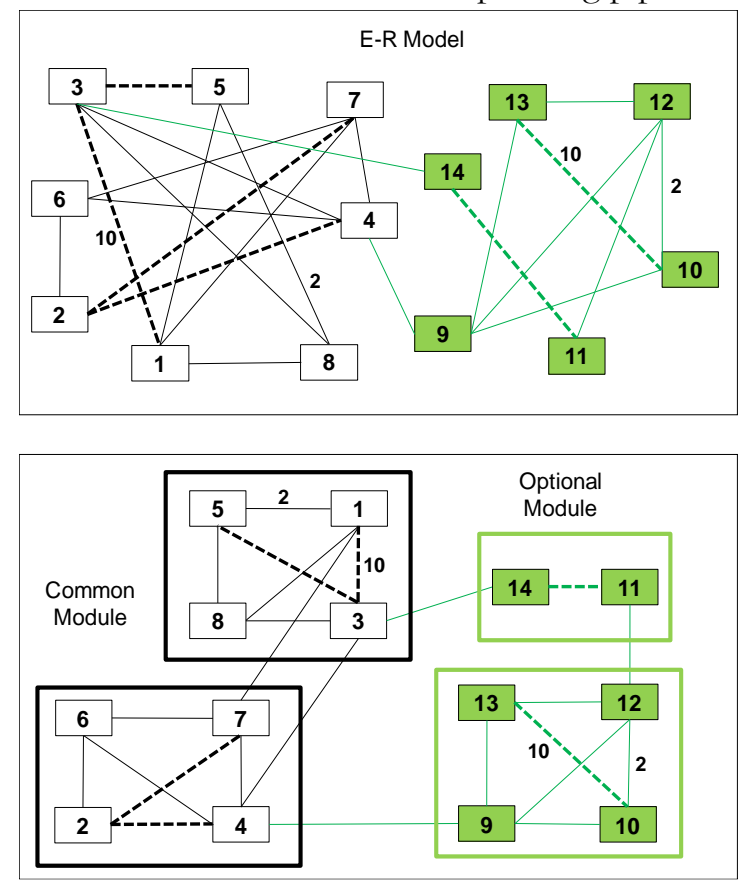

Fig. 3. Modularization process.
- Connections for optional parts: First, the weight is calculated in a similar manner to the common connections. Subsequently, the installation probability of the connections is multiplied with the weights.

- Once the weights are set, separate clusters of common parts and optional parts are prepared, thereby generating clusters (modules). The flow of the DSM procedure in this study is shown in Figure 3.
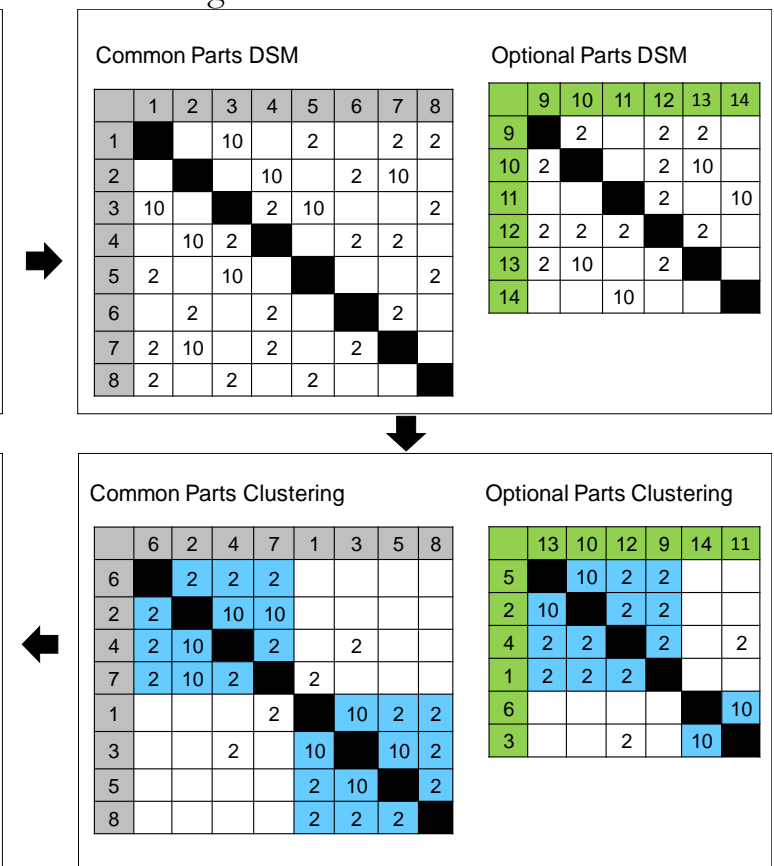


\section{Result and Discuss}

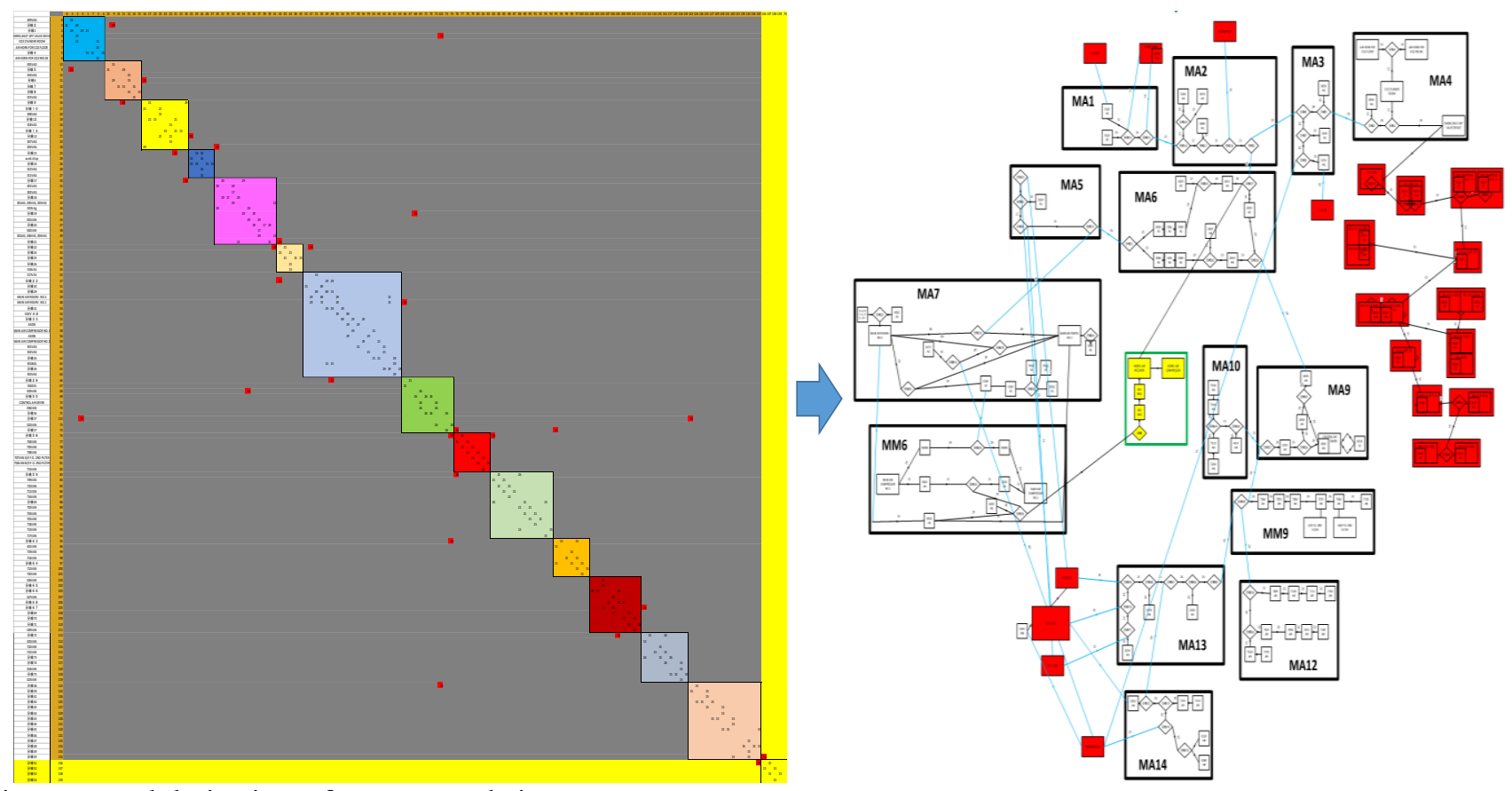

Fig. 4. Modularization of compressed air system.

Consider the example of compressed air piping system as denoted in Figure 4. which contains 250 common components and 5 optional components. Figure 4 shows the modularization result of compressed air piping system.

The group components inside the colored ones depict the optional components. While the red box illustrating the fixed parts, such as main engine, tank, and generator, and they should be situated outside the module. The modularization was realized for either a single ship or a series ships. Each module can be changed in capacity or size without changing the configuration. It is possible to configure a new piping system with a combination of all modules. There are 74 pipe connections among the modules and 357 connections inside the module.

The result of modularization for compressed air piping systems is described in the figure 4. Each piping system modularized using the DSM procedural concept. In order to evaluate the effectiveness of the proposed method, the modularization result of compressed air piping system is discussed below.

The result of modularization in compressed air piping system as denoted in the Figure 4, modules as the result from all ships in all series. In this case, 14 common modules and 1 optional module are generated. This result means that in the compressed air piping system, each individual ship in all series consists of 14 common modules. All ships have same number of the common modules. The differences are located in the module size and capacity of each series, according to the differences of the owner requirements. In a word, the commonness modularization concept is implemented in this research. The size and capacity differences of the module are not considered as the important point, because it not affected in the module configuration.

However, the optional module is adopted in several ships. In this case, the optional module is air receiver. In the adoption rate data, this module is adopted in the $25 \%$ of the total ships. It can be said that if the total ships were built in all series are 100 ships; therefore, 25 ships are equipped with this optional module. Furthermore, the configuration and number of common modules in all series are the same. However, the configuration and number of optional modules may be different.

In the series ship concept, the differences of part specification inside engine room is possible due to the differences of the owner requirements. However, in this concept, the differences only for several part as the additional requirement from the certain owner. Therefore, only in the particular ships are equipped with some optional part. In order to create the commonness modularization, common part and optional part should be separately. Common part for each system is modularized for all ships at the same time. In a word, the modularization of common part, come from the integration part lists of certain system in all series ships. As the result, the commonness of common module is obtained.

Subsequent, the optional part is modularized according to the additional part data from certain ship that equipped with additional part. Therefore, the optional part is not included in the common module. Optional part is modularized into some optional module. According to this result, the common part and optional part are modularized separately. 

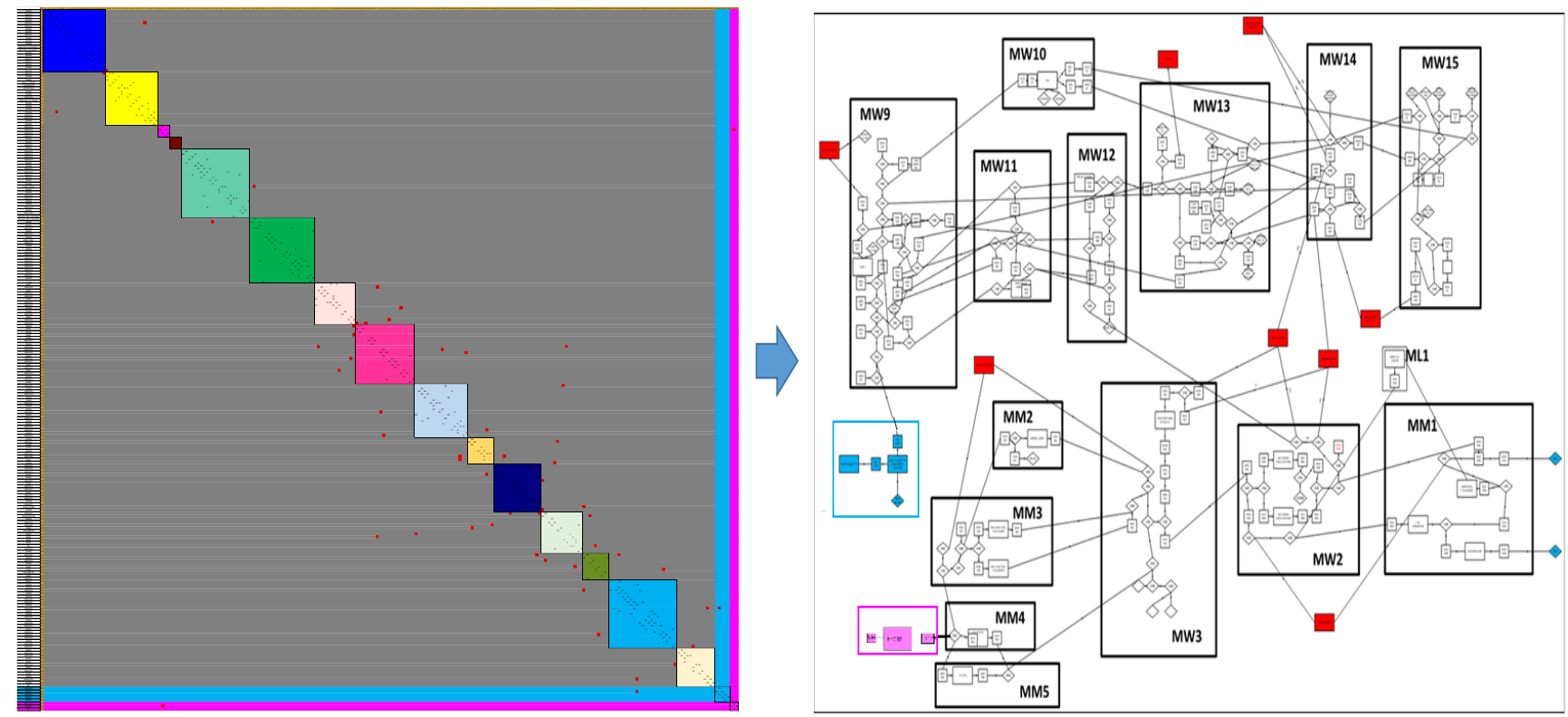

Fig. 5. Modularization of seawater cooling system.

Consider the example of a seawater system as shown in the Figure 5; it comprises 233 common and 8 optional components. This type of modularization is realized for a single ship or a series of ships, and also for ships belonging to various series types that could be established with 15 common and 2 optional modules. Each module can be varied in capacity or size with no change to its configuration. Therefore, it was possible to configure a new piping system combining all modules. The arrangement comprises 40 pipe connections between the grouped modules and 233 pipe connections within the modules.

The result of modularization in seawater piping system as denoted in the Figure 5, modules as the result from all ships in all series. In this case, 15 common modules and 2 optional modules are generated. This result means that in the seawater piping system, each individual ship in all series consists of 15 common modules. All ships have same number of the common modules. The differences are located in the module size and capacity of each series, according to the differences of the owner requirements. In a word, the commonness modularization concept is implemented in this research. The size and capacity differences of the module are not considered as the important point, because it not affected in the module configuration.

However, the optional module is adopted in several ships. In this case, the optional module is shoot collect tank and fine filter. In the adoption rate data, shoot collect tank module is adopted in the $25 \%$ of the total ships. It can be said that if the total ships were built in all series are 100 ships; therefore, 25 ships are equipped with this optional module (shoot collect tank module). Furthermore, the configuration and number of common modules in all series are the same. However, the configuration and number of optional modules may be different.
In the series ship concept, the differences of part specification inside engine room are possible due to the differences of the owner requirements. Therefore, only in the particular ships are equipped with some optional part. In order to create the commonness modularization, common part and optional part should be separately. Common part for each system is modularized for all ships at the same time. In a word, the modularization of common part, come from the integration part lists of certain system in all series ships. As the result, the commonness of common module is obtained. Subsequent, the optional part is modularized according to the additional part data from certain ship that equipped with additional part. Therefore, the optional part is not included in the common module. Optional part is modularized into some optional module.

The commonness modularization concept allows for the change of the part capacity and size without change in the module configuration. Since, the module design is obtained, that is possible for owner to require some changes related to the part properties inside the module. Figure 6 shows the illustration of module change in term of capacity and size.

Figure 6 shows, in case the owner requires change of the part capacity that effect of the module size, however, the configuration of module is not changed. For the example, module MW2 consists of two main parts; no. 1 S.W cooling Pump and no. 2 S.W cooling Pump. These pumps capacity are changed based on the owner requirement; therefore, the size of new pump is twice. Consequently, the size of module MW2 increased two times. However, the module configuration is not changed.

One of the some advantages of the proposed modularization concept in this study is to simplify the owner to require new ship type (piping system). Combine the common module and optional module obtain the new piping system type. In case of Figure 6, there are 15 
common modules and 2 optional modules in the seawater piping system. In case of the owner requires new type of seawater piping system, they just make a combination of these modules. For the example, the new type is consists of only 13 common modules excluding module MM4 and
MM5. Furthermore, only shot collect tank module is installed as the optional module.

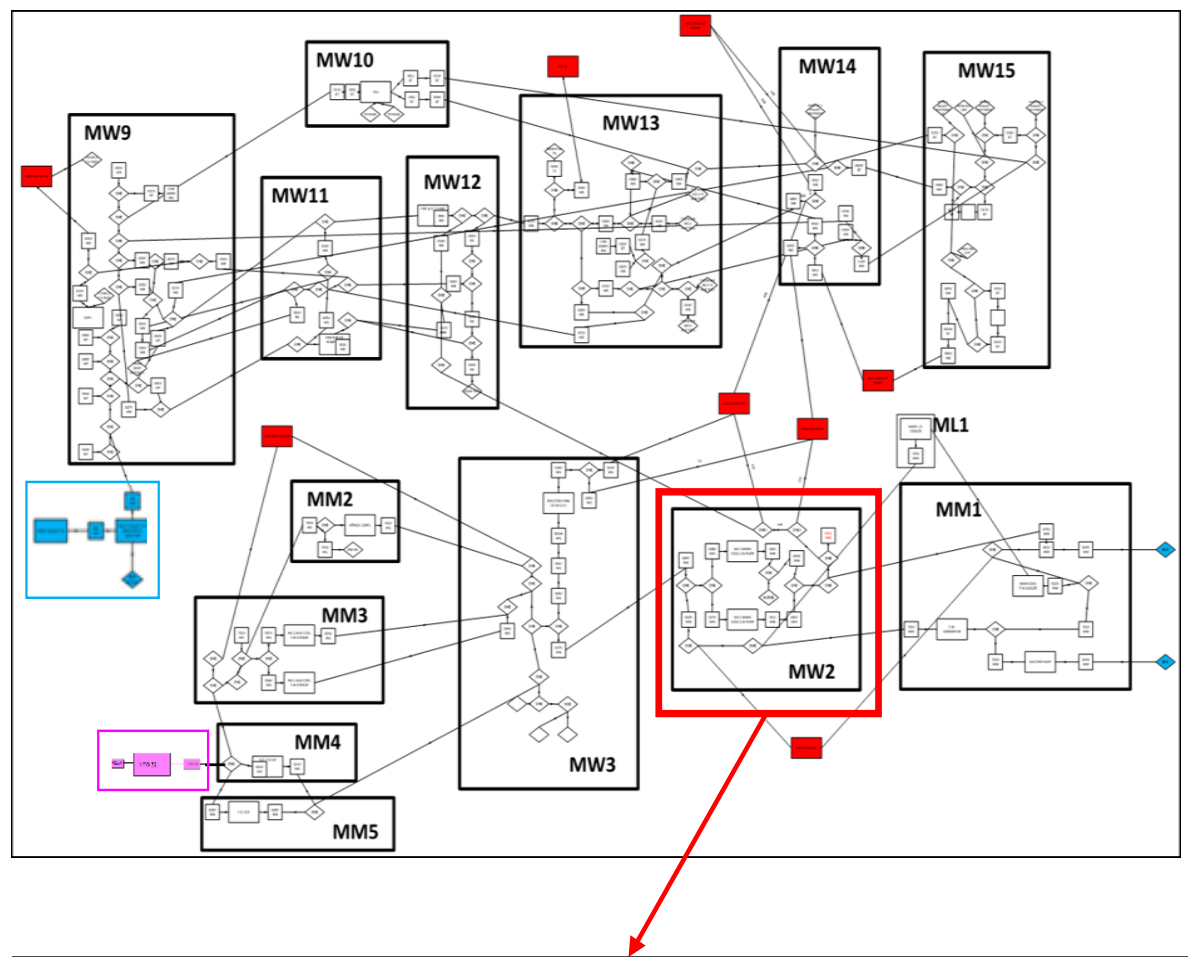

Module MW2 consists of 2 main part:

1. No.1 S.W Cooling Pump, Initial capacity 200 gallon/minute, pump size $2 \mathrm{~m} \times 1 \mathrm{~m} \times 1.5 \mathrm{~m}$

2. No.2 S.W Cooling Pump, Initial capacity 200 gallon/minute, pump size $2 \mathrm{~m} \times 1 \mathrm{~m} \times 1.5 \mathrm{~m}$

Owner want to change in to:

1. No.1S.W Cooling Pump, I nitial capacity 300 gallon/minute, pump size $2 \mathrm{~m} \times 2 \mathrm{~m} \times 1.5 \mathrm{~m}$

2. No.2 S.W Cooling Pump, Initial capacity 300 gallon/minute, pump size $2 \mathrm{~m} \times 2 \mathrm{~m} \times 1.5 \mathrm{~m}$

Fig. 6. Change of the module capacity and module size.

\section{Conclusion}

In this study, a new method of modularization of ship piping system inside engine room is proposed. The summarize of the results are:

- The modularization is addressed inconsideration of various series ships.

- In order to obtain the commonness of modularization, common part and optional part are modularized separately.

- Common part modularization is modularization for all common parts in each piping system for all series ships in the one time. Therefore, the integration common part list is defined before the modularization.

- Optional part modularization is modularization for all optional parts in each piping system for all series ships that equipped with additional part based on the owner requirement. This modularization is executed in one time. Therefore, the integration of optional part list is defined before the modularization.

- Design structure matrix (DSM) is adopted in order to modularize the part in each piping system. Therefore, E-R model is created before the DSM process.

- The result of modularization is fulfilled with the all requirements of modularization.

- Finally, effectiveness of modularization is evaluated.

\section{Acknowledgement}

This work is supported by Directorate of Research and Community Engagement, Universitas Indonesia, with scheme of Research Collaboration, contract number: NKB-1954/UN2.R3.1/HKP.05.00/2019. 


\section{References}

[1] A. Cort and W. Hills, "Space layout design using computer assisted methods," Naval Engineers Journal, vol. 99, no. 3, pp. 249-260, 1987.

[2] W. Hills and M. Wels, "An efficient compartmentation method for use in preliminary ship design," in International Conference on Computer Applications in Shipbuilding (ICCAS), 1989, pp. 141153.

[3] P. E. Jaquith, R. M. Burns, S. E. Dunbarr, B. J. Fontaine, H. A. Nelson, and J. L. Silveira, "Modular engine room design and construction for the strategic sealift ships," Journal of Ship Production, vol. 12, no. 4, pp. 230-243, 1996.

[4] R. Baade, F. Klinge, K. Lynaugh, F. Woronkowicz, and K.-M. Seidler, "Modular outfitting," Journal of Ship Production, vol. 14, no. 3, pp. 170-179, 1998.

[5] C. Tomassoni, T. Huynh, and T. Schiller, "Production-based design methodology for shipboard machinery spaces," Journal of Ship Production, vol. 19, no. 1, pp. 53-63, 2003.

[6] M. E. Sosa, T. R. Browning, and J. Mihm, "Studying the dynamics of the architecture of software products," in Proceedings of the ASME 2007 International Design Engineering Technical Conferences \& Computers and Information in Engineering Conference (IDETC/CIE 2007), Las Vegas, NY, September 4-7. 2007.

[7] A. MacCormack, J. Rusak, and C. Baldwin, "Exploring the structure of complex software design: An empirical study of open source and proprietary code," Management Science, vol. 52, no. 7, pp. 10151030, 2006.

[8] R. Schmidt III, T. Eguchi, S. Austin, and A. Gibb, "Adaptable futures: A 21st century challenge," in Changing Roles-New Roles, New Challenges, Rotterdam, the Netherlands, October 5-9, 2009.

[9] Q. Dong and D. E. Whitney, "Designing a requirement driven product development process," in Proceeding of ASME Design Engineering Technical Conferences, Pittsburgh, PA, 2001.

[10] P. J. Clarkson, C. S. Simons, and C. M. Eckert, "Predicting change propagation in complex design," Journal of Mechanical Design, vol. 126, no. 5, pp. 765797, 2004.

[11] C. M. Eckert, P. J. Clarkson, and W. Zanker, "Change and customisation in complex engineering domains," Research in Engineering Design, vol. 15, no. 1, pp. 1-21, 2004.

[12] T. Koga, T. Niwa, and K. Aoyama, "A modular design method for an engine room based on an integrated network description and division," in 10th International Marine Design Conference, 2009, pp. 1-9.

[13] R. Rubesa, N. Fafandjel, and D. Kolic, "Procedure for estimating the effectiveness of ship modular outfitting," Eng. Rev., vol. 31, no. 1, pp. 55-62, 2011.
[14] S. O. Erikstad, "Modularisation in shipbuilding and modular production," Working paper (IGLOMP2020) NTNU, Trondheim, 2009.

[15] S.-Y. Kim, B.-Y. Moon, and S.-C. Shin, "Evaluation criterion of machinery arrangement design in a ship engine room," Journal of Ship Production, vol. 25, no. 3, pp. 117-125, 2009.

[16] H. Kimura, "Automatic designing system for piping and instruments arrangement including branches of pipes," in International Conference on Computer Applications in Shipbuilding (ICCAS), 2011, pp. 93-99.

[17] B. C. Wu, G. S. Young, W. Schmidt, and K. Choppella, "Applying fuzzy functions and sequential coordination to optimization of machinery arrangement and pipe routing," Naval Engineers Journal, vol. 110, no. 6, pp. 43-54, 1998.

[18] D.-M. Lee, S.-Y. Kim, B.-Y. Moon, and G.-J. Kang, "Layout design optimization of pipe system in ship engine room for space efficiency," Journal of the Korean Society of Marine Engineering, vol. 37, no. 7, pp. 784791, 2013.

[19] S Helvacioglu, and M. Insel, "A reasoning method for a ship design expert system," International Journal of Knowledge Engineering and Neural Networks, vol. 22, no. 2, pp. 72-77, 2005.

[20] W. Niu, H. Sui, Y. Niu, K. Cai, and W. Gao, "Ship pipe routing design using NSGA-II and coevolutionary algorithm," Mathematical Problems in Engineering, vol. 2016, pp. 1-21, 2016.

[21] W. Wuuren and J. I. M. Halman "Platform driven development of product families: Linking theory with practice," in The Future of Innovation Studies Conference, Eindhoven, Netherlands, 2001.

[22] G. G. Rogers and L. Bottaci, "Modular production systems: a new manufacturing paradigm," Journal of Intelligent Manufacturing, vol. 8, pp. 147-156, 1997.

[23] Y. Wu, Y. Wang, X. Feng, and S. Feng, "A genetic algorithm based plant layout design methodology considering piping and safety. Chemical, Engineering Transactions, vol. 52, pp. 25-30, 2016.

[24] C. J. Lee, "Optimal multi-floor plant layout based on the mathematical programming and particle swarm optimization," Industrial Health, vol. 53, pp. 491-497, 2015.

[25] S. D. Eppinger and T. R. Browning, Design Structure Matrix Methods and Applications. MIT Press, 2012.

[26] U. Lindemann, M. Maurer, and T. Braun, "Structural Complexity Management. Berlin; Heidelberg, Germany: Springer-Verlag, 2009.

[27] A. K. Kamrani and S. M. Salhieh, Product Design for Modularity. Kluwer Academic Publisher, 2002.

[28] P. Chen, "The Entity-Relationship Model toward an un-fined View of Data," ACM Transaction on Database Systems, vol. 1, no.1, pp. 9-36, 1976. 


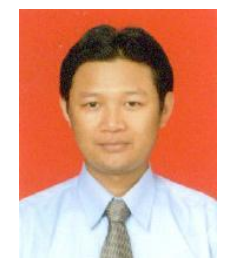

Gunawan was born in Wonosobo, Indonesia, in 1988. He received the B.Eng. and M.Eng. degrees in Naval and Marine engineering from the Universitas Indonesia, Indonesia, in 2010 and 2012 respectively. Then receive the Ph.D. degree in transportation engineering from Hiroshima University, Japan, in 2018. Now, he joined as assistant Professor in Universitas Indonesia. His research is about the optimization of supporting system related to the ship building technology.

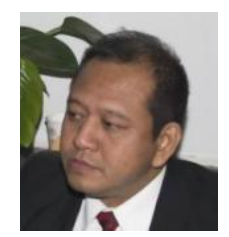

Yanuar received his B.S. degree in Naval Architecture from University of Indonesia, Indonesia, in 1986. He then received his Master of Eng. and Doctor of Eng. in Mechanical Engineering from University of Tokyo Metropolitan, Japan, in 1995 and 1998, respectively. Professor at Mechanical Engineering at University of Indonesia in Jakarta, Indonesia. His research project is about drag reduction in internal flow or external flow.

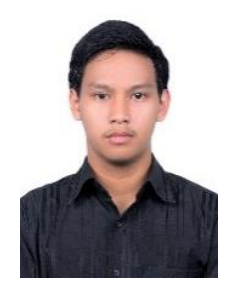

Farhan Aji Waskita was born in Jakarta, Indonesia, in 1998. He received the B.Eng degrees in Naval and Marine engineering from the Universitas Indonesia, Indonesia, in 2019. Now, he joined as assistant laboratory in Universitas Indonesia. His research is about the optimization of supporting system related to the ship building technology.

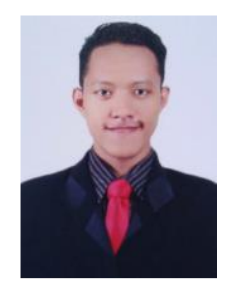

Arif Kurniawan was born in Jakarta, Indonesia, in 1997. He received the B.Eng degrees in Naval and Marine engineering from the Universitas Indonesia, Indonesia, in 2019. Now, he joined as assistant laboratory in Universitas Indonesia. His research is about the optimization of supporting system related to the ship building technology. 